\title{
Usage of Internet for Academic Purposes on University Students' Achievement: A Literature Review
}

\author{
Sumaiyah Jamaludin TS ${ }^{* 1}$, Kechik NA ${ }^{1}$, Saidi $\mathrm{S}^{1}$ and Chan CM${ }^{2}$ \\ ${ }^{1}$ Department of Medical Surgical Nursing, Kulliyyah of Nursing, International Islamic \\ University Malaysia, Malaysia \\ ${ }^{2}$ Department of Nursing Science, University of Malaya, Malaysia
}

\section{Research Article \\ Volume 2 Issue 1}

Received Date: December 15, 2017

Published Date: January 31, 2018

*Corresponding author: Thandar Soe Sumaiyah Jamaludin, Department of Medical Surgical Nursing, Kulliyyah of Nursing, International Islamic University Malaysia, Jalan Hospital Campus, 25100, Kuantan, Pahang, Malaysia, Tel: 0166092641; E-mail: sumaiyah@iium.edu.my

\begin{abstract}
The aim of this literature review was to evaluate the effectiveness of internet usage for academic purposes among healthrelated undergraduate students from various courses. This paper has highlighted for understanding more deeply on the effectiveness of internet usage among university students in their studies. This review found that socio economic status of students has both positive and negative significant effect on their academic achievement. Furthermore, students spend more than one hour online depended on the many factors that cause them to be online. The purposes of using the internet were varied as communication and academic search purposes. On the top of that, Google was the most used search engine and Pub Med was popular among the databases for their academic search among the students. From this literature review, it can be concluded that the students believed of using internet has improved on their academic performances but depending on the time they spent in the online internet.
\end{abstract}

Keywords: Internet Usage; Academic Achievement; Health Related University Students

\section{Introduction}

The Internet offers significant opportunities for accessing information in fields of life such as economics, education, and health by sharing and storing information. Internet has become a need in a person's life as it provides a gateway to vast information at the fingertip. In 2015, the Internet users in Malaysia from 15 years old and above were $71.1 \%$, increased by $14.1 \%$ compared in 2013 [1]. In fact, since internet was widely commercialized since 1990s, it not only provides information needed but also a place to let out stress by gaming online or socialize using Facebook, Twitter and Instagram. For University students, they are very knowledgeable about the internet uses and can use it for their studies too. Even a casual observation of today's University students will reveal cell phones being used, both overtly and covertly, in every possible campus setting, including the classroom [2]. 


\section{Nursing \& Healthcare International Journal}

Furthermore, it has a wide base that allows access to an enormous range of research information either as full publications, reports, summaries or abstracts. However, how well the usage of internet for academic purposes is still unknown. Nonetheless, Kam, et al. noted that studies with a primary emphasis on the use of Internet by university students as a source of health information are not common [3]. Therefore, this literature review was designed to search the related literature on the usage of internet among health-related undergraduate university students for their academic achievement.

\section{Methods}

This literature review was aimed to identify literature which gives evidence of a predefined content and quality that required to be discussed further. A pragmatic approach to the review was therefore adopted, primarily to enable a focused and technically manageable overview. The precise inclusion and exclusion criteria, and search strategies as followed.

\section{Study Eligibility Criteria}

The inclusion criteria were the studies written in English and the report carried data about health related universities students aged $\geq 17$ years old. The exclusion criteria were the studies carried out at art based universities students and the studies were written in other languages.

\section{Search Strategy}

The literature of studies was selected between September 2016 to March 2017 in order to summarize, synthesize and draw conclusion about a topic based on the evidence from the involved studies. The search strategy used the terms 'internet usage', 'nursing students' and 'academic achievement'. Subsequently, the search expands by linking the initial keywords including "university students". The search limited to English language articles within time frame from 2006 until March 2017. There were 54100 articles found. From that number, 50 articles were chosen for shortlisted. The researcher has chosen 22 articles which are the most suitable and related for this research topic.

\section{Databases}

Electronic database search that are relevant was done on the writer's online databases such as Springer link, ProQuest, Medscape and Mosby nursing consult and OvidMedline.

\section{Result}

Total of 22 papers were chosen to be discussed in this study regarding uses of internet for academic purposes in health-related university students. Participants in the selected studies were students from various universities who were taking health-related courses.

\section{Relationship between Students' Socio Economic and Their Academic Performances}

In a study involved 178 students from Kumasi Nursing and Midwifery Training College the SDA Nurses and Midwifery Training College found that sociodemographic background of the students had no influence on their academic performance in the nursing training as well as the licensure examination [4]. Another study done at medical students of King Abdulaziz university showed that financial factors such as the monthly income of the studied participant's family were not significant on their academic achievement [5]. According to Alos, et al. the home-related factors were discovered to have a low influence on student nurses' academic performance [6]. The indicator with the highest mean in this subset was 'I live far from school' and the indicator with the lowest mean was 'I have many brothers and sisters'. However, these findings were in contrast with another finding. A qualitative study involved 83 student nurses at University of Namibia (UNAM), Oshakati Campus Students revealed that their academic is determined by socio economic factors as students who do not have enough money claimed they perform poorly. According to the participants also students who do not have loans perform poorly because they cannot buy prescribed books [7]. Another study showed that the top five perceived causes of poor academic performance included: giving the students too many assignments 107 (53.2\%), parents' inability to provide all the text books needed by the student nurses $18(9.0 \%)$, student nurses lack all their basic needs $16(8.0 \%)$, lack of library and internet facilities $14(7.0 \%)$ and students' inability to understand the science subjects (4.5\%) [8]. Another study found that socio economic background effectiveness positively to the student academic performance which means the higher the socioeconomic status, the better their academic achievement [9]. A similar result found in a study among 294 students from University Jimma campus Ethiopia resulted that parents' social economic status is significantly related to academic performance of students as the study measured the items of social economic status and academic performance and the Pearson chi-square test of association gave a significance or p-value of 0.001 , 


\section{Nursing \& Healthcare International Journal}

which is less than alpha 0.05 which revealed that parents' social economic status is significantly related to academic performance of students [10].

Among 22 literatures been reviewed, only seven (7) literatures discussed on the effect of socio economic factors on student's achievement while the others only analyze the socio economic characteristics of the students without related them with the achievements. From the results, it showed that the economic statuses of the students have both positive and negative effectiveness to students' achievement in studies.

\section{How often do Students use the Internet?}

Singh, et al. (2013) analyzed total of 500 students of the Hamdard Institute of Medical Sciences and Research, Jamia Hamdard, New Delhi, AIIMS Jodhpur and SN Medical college Jodhpur [11]. From data collected, 256 (51.2\%) respondents used it daily, 178 (35.6\%) used the internet on weekly basis, while $66(13.2 \%)$ used the facility ones in a while. In the same study, about 335 (67\%) students admitted that they spend $45 \mathrm{hr} / \mathrm{wk}$ along with internet while 115 (23\%) spend time in between 35$45 \mathrm{hr} / \mathrm{wk}$ and rests of them spend less than $35 \mathrm{hr}$. In a study among 171 first-year medical students from 4 different medical colleges of the University of Jordan, Almarabeh, et al. found that $166(97 \%)$ uses internet daily and remaining $11(3 \%)$ use internet in weekly basis [12]. Among 109 medical students of Shahid Sadoughi University of Medical Science, Iran, 40 (61.5\%) of the female students used the internet at least once a week, this frequency was 17 (38.5\%) for male students [13]. Chen \& Peng in a study involved 26,307 students in 156 universities and colleges in Taiwan analyzed that participants' average total weekly time on the Internet was 17 hours, with an average of 4.15 hours a week spent on making friends or chatting, 3.59 on searching for academic information, and 3.21 hours spent on searching for nonacademic information. Online games occupied 2.57 hours, and checking e-mail occupied 1.35 hours a week [14]. Another study involving 193medical students at Taibah University, the majority of male students $56(66.3 \%)$ spent 2- 4 hours while female students 47 (44.9\%) spent 5-7 hours on internet. Regarding the time spent on internet in relation to students' GPA, the researcher found that the majority of student (103 students) $53.4 \%$ use the internet for 2-4 hours and most of them are of 4-4.49 GPA [15]. Obasola \& Agunbiade [16] observed the frequency of internet usage among 400 students in eight faculties in University of Ibadan and found that the frequency of Internet use on a daily basis was on the average 135 (33.7\%) when compared with those who access the Internet for health-related information on a weekly basis $89(22.2 \%)$. It could be observed that 256 (73\%) from 350 respondents in the Departments of Accountancy and Microbiology, University of Maiduguri, Nigeria agreed that they surf the Internet between $0-2$ days a week, 24 (7\%) browse $3-5$ hours in a week, $10(3 \%)$ browse $6-7$ minute in a week, while $60(17 \%)$ of the respondents refused to respond to the question. The analysis shows that majority of the respondents preferred between 0-2 days as regards how often the respondents browse the Internet in a week [17]. About one-fifth (22.8\%) of the respondents used Internet for a duration of more than 3 hours per week. From a total of 272 medical undergraduates of Subharti Medical College, Meerut, the result among the various cohorts studied, prevalence of students using Internet for more than 3 hours per week was highest (47.0\%) among thirdyear students and minimum (4.1\%) among the first-year students. A total of $29.4 \%$ of the males were using Internet for more than 3 hours per week compared to females (14.3\%). The difference in duration of Internet use was significant between the various cohorts and also between the sexes [18]. Among 142 medical students of PESIMSR, Kuppam, Andhra Pradesh, India, 76.64\% used internet daily, $16.19 \%$ once a week, $1.41 \%$ fortnightly and $2.81 \%$ monthly [19]. Another study by Hogan\& Sweeney [20] found that among 922 students in University in Ireland, the findings indicated that the majority of participants $72.4 \%(n=639)$ used the internet several times a day, $16.2 \%$ (143) used it once a day and the remainder used it several times a week $(11.1 \%$, $n=98)$, or less $(0.3 \%, n=3)$.

Mostly students have access to internet once in a week. The duration when accessing of the internet varied but from the studies, students spend time surfing the internet are more than one hour. The duration of surfing internet also different according to the purposes of the students being online like searching academic material and chatting.

A total of ten (10) studies discussed on the frequency of the usage of internet among students while the other 12 studies did not.

\section{For what Purpose do Students use the Internet most?}

Kumar, et al. [19] studied the usage of internet Among 142 medical students of PESIMSR, Kuppam, India and revealed about $82(57.7 \%)$ of the students used internet for completing assignments and $73(51.4 \%)$ for course 


\section{Nursing \& Healthcare International Journal}

related entertainment, 112 (78.8\%) used for chatting purpose, 97 (68.3\%) for music downloads, $86(60.5 \%)$ for checking emails $58.4 \%$ for playing games and $54,2 \%$ for watching movies. Chen \&Peng in a study involved 26,307 from 156 universities in Taiwan revealed that women reported more time spent on searching for academic information $(\mathrm{t}=-25.34)$, making friends and chatting $(\mathrm{t}=\mathrm{-}$ 2.72), shopping ( $t=-15.76)$ and checking e-mail $(t=-13.75)$ than men [14]. Men reported more time spent on browsing porn $(\mathrm{t}=25.01)$ playing online games $(\mathrm{t}=$ 44.82), and browsing for stock information $(t=9.99)$ than women. A study done among 350 respondents from Departments of Accountancy and Microbiology, University of Maiduguri, Nigeria showed that 158 (45\%) of the respondents use the Internet to search for relevant academic materials, $46(13 \%)$ use it to send and receive E-mails, 7 (2\%) use it as a result of migration to America or Europe, $25(7 \%)$ use it to enable them satisfy their lecturers, while 109 (31\%) choose none of the above; 7 (2\%) of the respondents left the question unanswered [17]. Montagni, et al. did a research in four universities in France, Ireland, Italy and Spain and found that among 2366 respondents from computer science, law and nursing courses, most students used the Internet to search for information on health issues for themselves (62.5\%), but they also looked for information for family or friends (45.1\%) or just out of curiosity (36.5\%) [21]. Mashiri compared the usage of internet between the 100 first year and final year students of the undergraduates students at a local university in Zimbabwe and found that although more final year students claimed to use the internet for finding books, $10 \%$ of finals compared to $2 \%$ of first years said they never used it for finding books. Generally students use the internet to find information about the university and barely any have not used it for finding books [22]. Majority of the students, both first and final years use it to find information from websites. An average number of students download software. $46 \%$ of the finals use the internet for downloading notes against $26 \%$ of the first years. $56 \%$ of the finals use internet for finding journal articles while only $22 \%$ of the first years use it. Students hardly use the internet for communicating with lecturers. $62 \%$ of the first years use the internet for communicating with friends and other students more often against $46 \%$ of the finals. Jali, et al. studied the usage of internet among 340 of first to fourth year Bachelor of Dental Surgery (BDS) and internship students, studying in Vyas Dental College and Hospital Jodhpur, India and found commonly students use internet for web browsing (37. 4\%), E-mail(30.9\%)and research activity ( 23.5\%) respectively [23]. Hogan\& Sweeney (2013) reported that among 922 students in University in Ireland, from the total response of 883 , majority of them used social networking sites $(85.5 \%, \mathrm{n}=755)$, primarily to stay in contact with friends and family, particularly those who live abroad (85.2\%) [20]. The findings also indicated that $66.1 \%(n=584)$ of participants had used the internet to search for general health information. The findings indicated that $2.7 \%(\mathrm{n}=23)$ of participants had used online therapy, $5 \%(\mathrm{~N}=43)$ had used chat rooms and $15.9 \%(n=136)$ had used forums/discussion boards for support with a health related difficulty. A study among 500 medical students of the Hamdard Institute of Medical Sciences and Research, Jamia Hamdard, New Delhi, AIIMS Jodhpur and SN Medical college, as many as 183 (36.6\%) respondents admitted that they mostly use the internet for mailing, while $176(35.2 \%)$ used it mostly for academic purpose, $86(19.2 \%)$ used it most for fun, while $50(10 \%)$ used it for social networking sites. One respondent $5(1 \%)$ did not respond to this question [11]. From the response of 190 medical students at Taibah University, it is found that the main purpose of using the internet among female medical students was for studying (65.4\%), while the male students mainly used the internet to keep in touch with friends and family (67.4\%) [15]. Senyuva \& Kaya conducted a study involving 498 nursing undergraduate in one of the oldest university in Turkey and found access information (education), 70.3\% used it for chatting, $24.9 \%$ for playing games, $16.5 \%$ for meeting new people, $10.4 \%$ for following up on news and learning exam results, and $8.0 \%$ for shopping [24]. $62.2 \%$ stated that they accessed the Internet through their personal computers, $60.4 \%$ used the computer room at the school, $36.3 \%$ used Internet cafes, and $26.9 \%$ used their friends' computers.

From the studies, it is revealed that students use internet for many purposes. However, most students were found using the internet for searching the relevant material for their studies. The other purposes of using internet among students are for socializing with friends and families through chatting and email. The students also use internet for entertainment like watching videos and gaming online.

Total of ten out of 22 studies observed the purposes of using internet among students while the other 12 did not.

\section{Is there any Relationship between Students' Use of the Internet and Their Academic Performance?}

In a study among 139 students of health colleges in University of Dammam, Saudi Arabia, the students were 


\section{Nursing \& Healthcare International Journal}

asked to mention if there are significant differences among the five health colleges in terms of the use of Internet for increasing their performance, helping them in their research projects, and the importance of having wireless Internet connection in each college. $89 \%$ of the participants agreed that the use of the Internet was important for all of the courses in their colleges [25]. The study agrees with a study by that found in order to assess the attitudes towards ICT, 171 first-year medical students from 4 different medical colleges of the University of Jordan were asked whether they felt that medical education would be effective without ICT and asked if they feel that the internet has positive effect on their academic performance. The $77 \%$ of respondents agree that the medical education will not be effective without ICT tools [12]. The $91 \%$ of students agree that the internet has a positive effectiveness on academic performance. A study that shows similar opinion is by Ogedebe in a study among 350 respondents from Departments of Accountancy and Microbiology, University of Maiduguri, Nigeria indicated clearly that, $8 \%$ believed that their GPA has improved remarkably as a result of the use of the Internet, $6 \%$ of the respondents agreed that their GPA has been declining, 28\% responded that it aids them in preparing better for CA and semester examinations, while $22 \%$ were indifferent about the options and therefore did not respond [17]. Mashiri compared the usage of internet between the 100 first year and final year students of undergraduate students at a local university in Zimbabwe and their results have shown that internet enhances the quality of learning, but its use for academic purposes is on the low [21]. Senyuva\& Kaya conducted a study involving 498 nursing undergraduate in one of the oldest university in Turkey found that the conceptual categories did not show any difference according to the grades of the nursing students, the secondary school they graduated from, Internet use habits, their primary purpose of Internet use, and where they connected to the Internet ( $p>0.05)$ [24] connected to the Internet $(p>0.05)$. Another result shows that frequency of using internet give different effectiveness on academic as from 26307 students participated in 156 universities and colleges in Taiwan showed differences in academic grades $(F=35.67, p<0.001)$ and learning satisfaction $(F=23.40, p<0.001)$ between heavy and no heavy Internet users were statistically significant. Non heavy users had better grades and greater learning satisfaction than heavy users [14]. However, time spent on different forms of social networking had a significant difference on the student's performance. Shawaa, et al. in a study involving 359 undergraduate students at Medical Faculty of King Abdulaziz analyzed that 110 (60.7\%) students spent less than 2 hours on internet, thus acquire high GPA while students with low GPA spent more than 3 [5]. Albouq, et al. (2015) found that the among medical students at Taibah University, Madinah, majority of student 103 students (53.4\%) use the internet for 2-4 hours and most of them are of 4-4.49 GPA [15]. 169 students $(87.6 \%)$ think that using internet provide them enough opportunities to promote themselves and their activities comparing to 24 students (12.4\% ) don't think so. The results revealed that 104 students (53.9\%) think that their grades and school work suffers because of the time they spend online, while 89 students $(46.1 \%)$ don't think so.

From the studies, the usage of internet has different effectiveness to students. Some students in the studies have affected positively by using internet but some are not. The duration of using internet also give effectiveness to the students as one of the study revealed non heavy users have positive effectiveness on the academic achievement. Another study also revealed that the internet has no effect at all on their academic achievement.

The totals of seven (7) studies analyze the effectiveness of internet usage on academic performance of the students while the other 15 did not. The other studies analyzed the various factors that affect the academic achievement of students such as access to resources, the facilities in the universities, self motivation and study habit.

\section{What is/are the Website/S used by Students for Searching Information?}

Al-Hariri, et al. searched in a study among 139 students of health colleges in University of Dammam, Saudi Arabia and when participants were asked which search engines they were using to obtain required information, all of them indicated that they were using Google [25]. In order to assess the attitudes towards ICT, 171 first-year medical students from 4 different medical colleges of the University of Jordan were asked about commonly used website and the study revealed that the common accessed website is Google, followed by Social networking Sites, Yahoo, and PubMed [12]. In a study about the usage of internet Among 142 medical students of PESIMSR, Kuppam, Andhra Pradesh, India The main accessed website reported among UG students was google $(98.59 \%)$ followed by Yahoo (3.5\%), Bing (0.7\%), MSN (0.7\%) and opera mini (0.7\%) [19]. Among 109 medical students of Shahid Sadoughi University of Medical 


\section{Nursing \& Healthcare International Journal}

Science, Yazd, Iran, the internet sites that medical students used more to access subjects on medical topics was $60.6 \%$ Pub Med, 34.9\% medical journals and $21.1 \%$ others [13]. Ogedebe in a study among 350 respondents from Departments of Accountancy and Microbiology, University of Maiduguri, Nigeria, it could be observed that $37 \%$ of the respondents visit yahoo's home page, $15 \%$ visit Goggle's home page while 28\% visit other Websites [17]. The other $20 \%$ of the respondents neglected the question. The study reported that among 922 students in University in Ireland, from the total response of 883 participants predominantly used Google as a search engine $(98.9 \%, n=870)$, others reported using Yahoo $(14.8 \%, \mathrm{n}=130)$ and $\operatorname{MSN}(11.8 \%, 104)$. Individual participants also reported using, Blackle, Firefox, Ixquick, Altavista, Metacrawler, Cuil, Dogpile, and Shareminer [20]. Jali, et al. studied the usage of internet among 340 of first to fourth year Bachelor of Dental Surgery (BDS) and internship students, studying in Vyas Dental College and Hospital Jodhpur, India and found that Google is a common search engine used (80.9\%), followed by PubMed (10.3\%) and Yahoo (6.2\%) [23]. None of the students have ever used google and $84 \%$ of the finals use it more often compared to $78 \%$ of the first years. Mashiri compared the usage of internet between the 100 first year and final year students of undergraduate students at a local university in Zimbabwe and found that Google is commonly used than yahoo [21]. A significant number has not used meta search engines such as dogpile and info.com. $18 \%$ of finals use academic. us compared to $10 \%$ of the first years. Wikipedia is popular among the first years, unlike with the finals. $20 \%$ of the finals use the online dictionary very often while $16 \%$ of the first years use it.

The most common search engine used by students is Google as Google is mentioned in all studies above. The second most used is Yahoo while students chose PubMed as the main website to find information related to health. Other websites used might be different as result of different countries and universities.

The total of eight (8) researches reviewed on the common websites used by undergraduates students while the other 14 did not.

\section{Discussion}

The purpose of this literature review is to find the gap within the existing literature related to the effectiveness of internet usage for academic purposes on universities students' achievement.
There were not enough resources to find the usage of internet and the effectiveness on academic especially among Malaysian students. The studies in this literature were done mostly in India and Middle East countries where the academic methods and socio demographic data are different from Malaysia. Four (4) studies are from India, two (2) from Ireland and European countries respectively, two (2) from Saudi Arabia, and one (1) each from Turkey, Jordan and Iran. A study is from Taiwan and another one from Philippines. The rest are from African countries which are; 3 (Nigeria), one (Kenya), one (Zimbabwe), one (Ethiopia), one (Ghana) and one (Namibia).

\section{Limitation of the Study}

The review is not only focus on one certain course only due to lack of resources. The review studies done about universities students from different courses; not only nursing, medical or sciences courses only. There are studies done at different universities involving thousands of students like done by Montagni, Donisi, Tedeschi, et al. and Chen \& Peng [14,22]. The writer intended to do systematic approach in this literature. The second stage for systematic review is a search for relevant data from research that matches certain criteria. For example, the writer should only select research that is good quality and answers the defined question. But, due to limited of studies, the writer has widened the criteria of the undergraduate students from focusing at a certain course to various courses.

\section{Conclusion}

Internet usage among health related university students is not only for their academic purposes but also for them to socialize, entertainment purposes and others. The effectiveness of internet usage for academic purposes also gives different effectiveness in their academic achievement due to many other external factors such as socioeconomic, study habit and facilities resources. The usage of internet among the health related university students should be explored more so that their studies are benefited from internet usage.

\section{Acknowledgements}

We would like to express our appreciation to International Islamic University Malaysia (IIUM) for funding this study (RIGS16-140-0304). 


\section{Nursing \& Healthcare International Journal}

\section{References}

1. Department of Statistic (2016) ICT Use and Access by Individuals and Households Survey Report, Malaysia, 2015.

2. Lepp A, Barkley EJ, Karpinski AC (2015) The Relationship Between Cell Phone Use and Academic Performance in a Sample of US College Students. SAGE 5(1).

3. Kam J, Stanszus D, Cheah J, Heerasing N, Yi TS (2010) The Internet as a Health Information Source for University Students. Australian Medical Student Journal.

4. Amankwaa I, Agyemang Dankwah A, Boateng D (2015) Previous Education, Sociodemographic Characteristics, and Nursing Cumulative Grade Point Average as Predictors of Success in Nursing Licensure Examinations. Nursing Research and Practice 682479: 8.

5. Al Shawwa L, Abulaban AA, Abulaban AA, Merdad A, Baghlaf S, et al. (2015) Factors potentially influencing academic performance among medical students. Adv Med Educ Pract 6: 65-75.

6. Alos SB, Caranto LC, David JJT (2015) Factors Affecting the Academic Performance of the

Student Nurses of BSU. International Journal of Nursing Science 5(2): 60-65.

7. Pinehas LN, Mulenga E, Amadhila J (2017) Factors that hinder the academic performance of the nursing students who registered as first years in 2010 at the University of Namibia (UNAM), Oshakati Campus in Oshana, Namibia. Journal of Nursing Education and Practice 7(8).

8. Dimkpa Daisy I, Inegbu, Buloubomere (2013) Student Nurses Perception of Poor Academic Performance in Bayelsa State, Nigeria. Global Journal of Human Social Science Linguistics \& Education 13(14).

9. Okioga CK (2013) The Effectiveness of Students' Socio-economic Background on Academic Performance in Universities, a Case of Students in Kisii University College. American International Journal of Social Science 2(2).

10. Akessa GM, Dhufera AG (2015) Factors that Influences Students Academic Performance: A Case of
Rift Valley University, Jimma, Ethiopia. Journal of Education and Practice 6(22).

11. Singh B, Gupta R, Garg R (2013) Study of Medical Students and Internet Usage. International Journal of Scientific and Research Publications 3(5): 5.

12. Almarabeh T, Rajab L, Majdalawi YKH (2016) Awareness and Usage of Computer and Internet among Medical Faculties' Students at the University of Jordan. Journal of Software Engineering and Applications 9(5): 147-154.

13. Ayatollahi A, Ayatollahi J, Ayatollahi F, Ayatollahi R, Shahcheraghi SH (2014) Computer and Internet use among Undergraduate Medical Students in Iran. Pak J Med Sci 30(5): 1054-1058.

14. Chen YF, Peng SS (2008) University Students' Internet Use and Its Relationships with Academic Performance, Interpersonal Relationships, Psychosocial Adjustment, and Self Evaluation. Cyberpsychol Behav 11(4): 467-469.

15. Albouq N, Hafiz B, Qasem A, Ekhmimi Y (2015) Prevalence of Internet Usage Among Medical Students At Taibah University And Its Impact On The Academic Performance, Madinah, Kingdom Of Saudi Arabia, 2015. European Journal of Pharmaceutical and Medical Research 3(7): 110-113.

16. Obasola OI, Agunbiade OM (2016) Online Health Information Seeking Pattern Among Undergraduates in a Nigerian University. SAGE Open 6(1).

17. Ogedebe PM (2012) Internet Usage and Students' Academic Performance in Nigeria Tertiary Institutions: A Case Study of University of Maiduguri.Academic Research International 2(3): 336-345.

18. Maroof KA, Parashar P, Bansal P (2012) How are our medical students using the computer and internet? A study from a medical college of north India. Niger Med J 53(2): 89-93.

19. Kumar SB, Veena CN, Vastrad BC, Nandan TM (2016) Awareness and use of internet services among first MBBS students. International Journal of Research in Medical Sciences 4(12): 5261-5264.

20. Horgan A, Sweeney J (2013) University students' online habits and their use of the Internet for health 


\section{Nursing \& Healthcare International Journal}

information. Computers Informatics Nursing 30(8): 402-408.

21. Montagni, Donisi V, Tedeschi F, Parizot I, Motrico E, et al. (2016) Internet use for mental health information and support among European university students: The e-MentH project. SAGE 2: 1-16.

22. Mashiri E (2013) First year and final year Undergraduate Students' Academic use of Internet. Case of a Zimbabwean University. Information and Knowledge Management 3(10).

23. Jali PK, Singh S, Babaji P, Chaurasia VR, Somasundaram P, et al. (2014) Knowledge and attitude about computer and internet usage among dental students in Western Rajasthan, India. J Int Soc Prev Community Dent 4(1): 29-34.

24. Senyuva E, Kaya H (2013) Metaphors for the Internet Used by Nursing Students in Turkey: A Qualitative Research. Egitim Arastirmalari-Eurasian Journal of Educational Research (50): 87-106.

25. Al Hariri TM, Al Hattami AA (2014) Utilization of internet by health colleges students at the University of Dammam. Journal of Taibah University Medical Sciences 10(1): 66-73. 